\title{
Degree of anthropogenic land disturbance controls fluvial sediment hysteresis
}

\author{
Amirreza Zarnaghsh ${ }^{1}$ and Admin Husic ${ }^{1 *}$ \\ ${ }^{1}$ Dept. of Civil, Environmental and Architectural Engineering, University of Kansas
}

*Admin Husic, ahusic@ku.edu, 2134B Learned Hall, University of Kansas, Lawrence, KS 66045

Supporting information contains 10 pages (S1 through S10): this cover, 4 tables, and 5 figures. 
Table S1. Summary of runoff, antecedent, and rainfall variables used in the analysis of hysteresis and suspended sediment controls

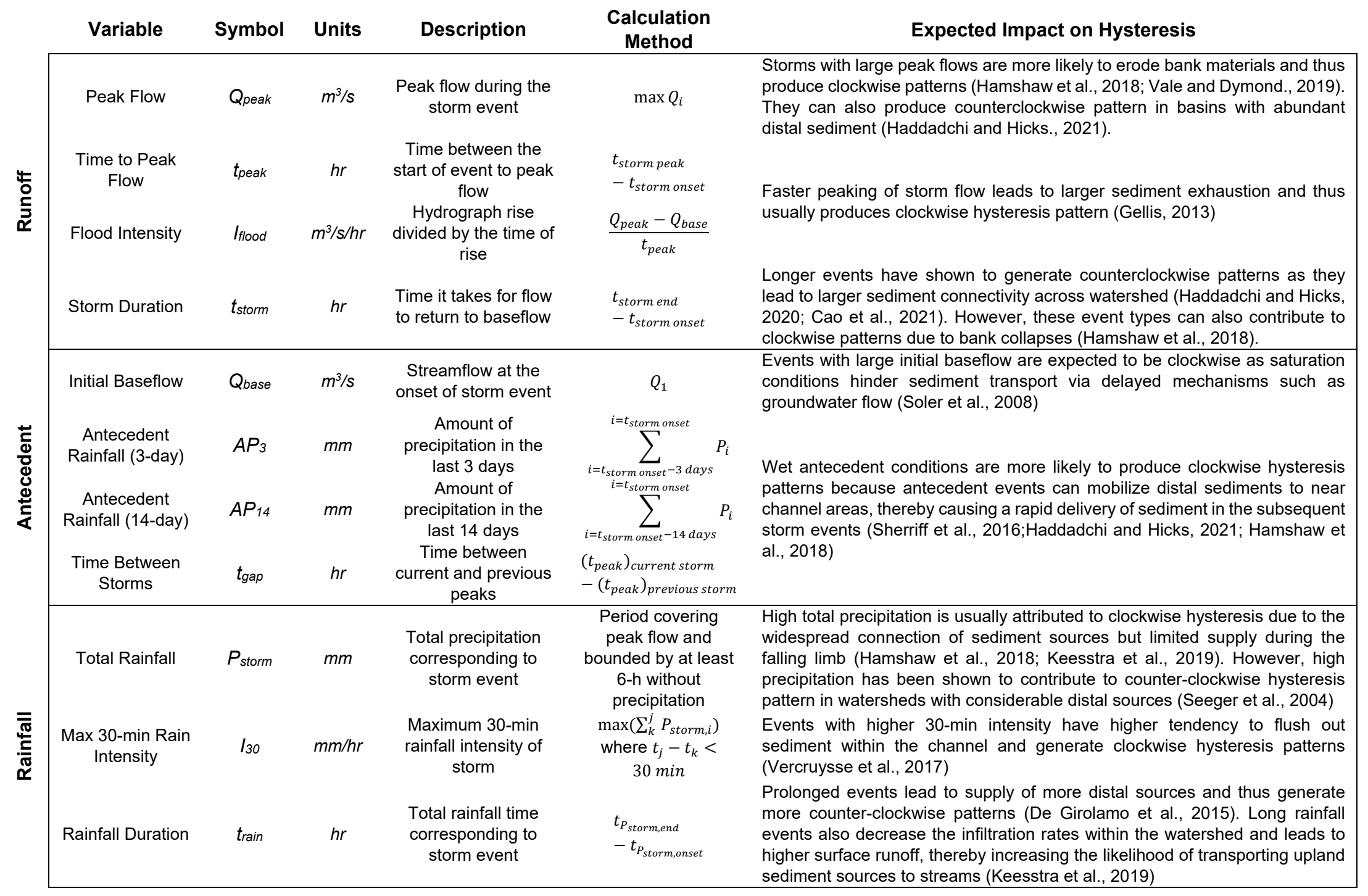


Table S2 Percentage of storm events categorized by hysteresis pattern. $\mathrm{CW}=$ clockwise, $\mathrm{CCW}=$ counter-clockwise, $\mathrm{F} 8=$ figure-eight, and $\mathrm{X}=$ complex. $\mathrm{HI}=$ hysteresis index and $\mathrm{FI}=$ flushing index.

\begin{tabular}{|c|c|c|c|c|c|c|c|}
\hline \multirow{2}{*}{ Watershed } & \multirow{2}{*}{$\begin{array}{l}\text { Number } \\
\text { of storms }\end{array}$} & \multicolumn{4}{|c|}{ Hysteresis shape characterization (\%) } & \multirow{2}{*}{$\begin{array}{c}\text { Mean } \\
\text { HI }\end{array}$} & \multirow{2}{*}{$\begin{array}{c}\text { Mean } \\
\text { FI }\end{array}$} \\
\hline & & CW & $\mathrm{CCW}$ & F8 & $x$ & & \\
\hline Kill Creek & 66 & 35.4 & 36.9 & 16.9 & 10.8 & -0.02 & 0.59 \\
\hline Cedar Creek & 93 & 33.0 & 34.1 & 22.7 & 10.2 & -0.01 & 0.54 \\
\hline Blue River & 164 & 15.3 & 36.2 & 41.1 & 7.4 & -0.11 & 0.45 \\
\hline Mill Creek & 233 & 10.3 & 64.7 & 16.5 & 8.5 & -0.23 & 0.56 \\
\hline Indian Creek & 293 & 6.5 & 56.2 & 25.3 & 12.0 & -0.16 & 0.71 \\
\hline
\end{tabular}


Table S3 Mean event-scale statistics for the studied watersheds, including the mean rainfall for a generated storm event, the inter-arrival time between events, the duration of events, and the increase in discharge from pre-event baseflow.

\begin{tabular}{lcccc} 
Watershed & $\begin{array}{c}\text { Event Rainfall } \\
(\mathbf{m m})\end{array}$ & $\begin{array}{c}\text { Inter-Arrival } \\
\text { Event Times (d) }\end{array}$ & $\begin{array}{c}\text { Storm } \\
\text { Duration (hr) }\end{array}$ & $\begin{array}{c}\text { Discharge } \\
\text { Increase }\left(\mathbf{m}^{\mathbf{3}} \mathbf{s} \mathbf{s}\right)\end{array}$ \\
\hline Kill Creek & 36 & 17.5 & 9.2 & 16.8 \\
Cedar Creek & 33 & 15.5 & 11.5 & 12.3 \\
Blue River & 32 & 13.5 & 12.0 & 25.3 \\
Mill Creek & 22 & 8.4 & 8.4 & 21.9 \\
Indian Creek & 22 & 8.8 & 6.1 & 29.9 \\
\hline
\end{tabular}


Table S4 Spectral slope of 15-minute streamflow, turbidity, sediment concentration, and sediment load time-series.

\begin{tabular}{lcccc} 
& \multicolumn{4}{c}{ Spectral slope $(\boldsymbol{\beta})$} \\
\cline { 2 - 5 } Watershed & Streamflow & Turbidity & $\begin{array}{c}\text { Sediment } \\
\text { concentration }\end{array}$ & $\begin{array}{c}\text { Sediment } \\
\text { load }\end{array}$ \\
\hline Kill Creek & -4.56 & -2.30 & -2.28 & -2.49 \\
Cedar Creek & -3.70 & -2.18 & -2.12 & -2.05 \\
Blue River & -4.37 & -2.03 & -2.04 & -2.39 \\
Mill Creek & -4.04 & -2.58 & -2.58 & -3.31 \\
Indian Creek & -4.01 & -1.96 & -1.92 & -2.36 \\
\hline
\end{tabular}



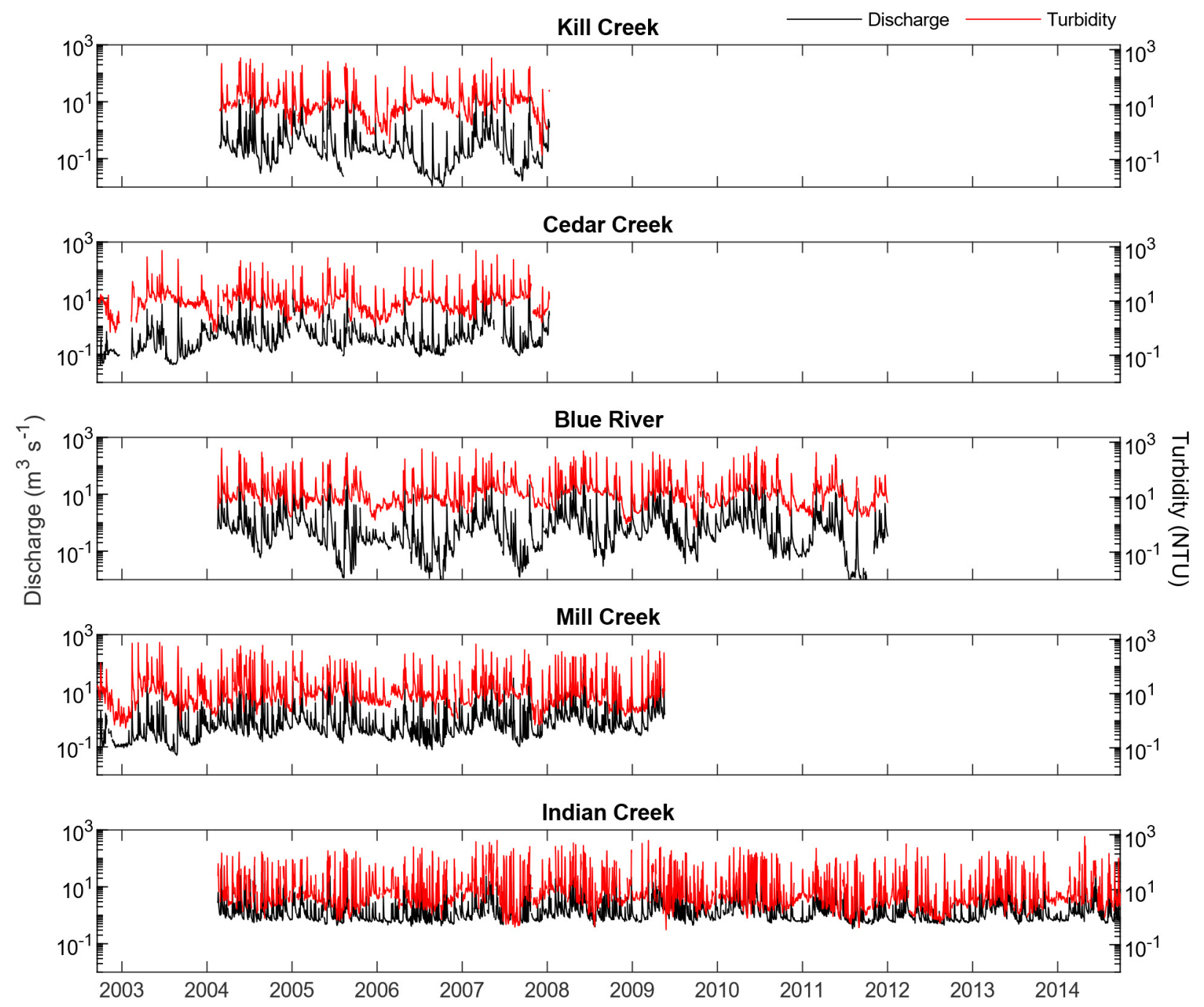

Figure S1 Mean daily stream discharge and turbidity sensor data at the five watersheds. Note: logarithmic y-axes are used to distinguish patterns more readily between sites. 

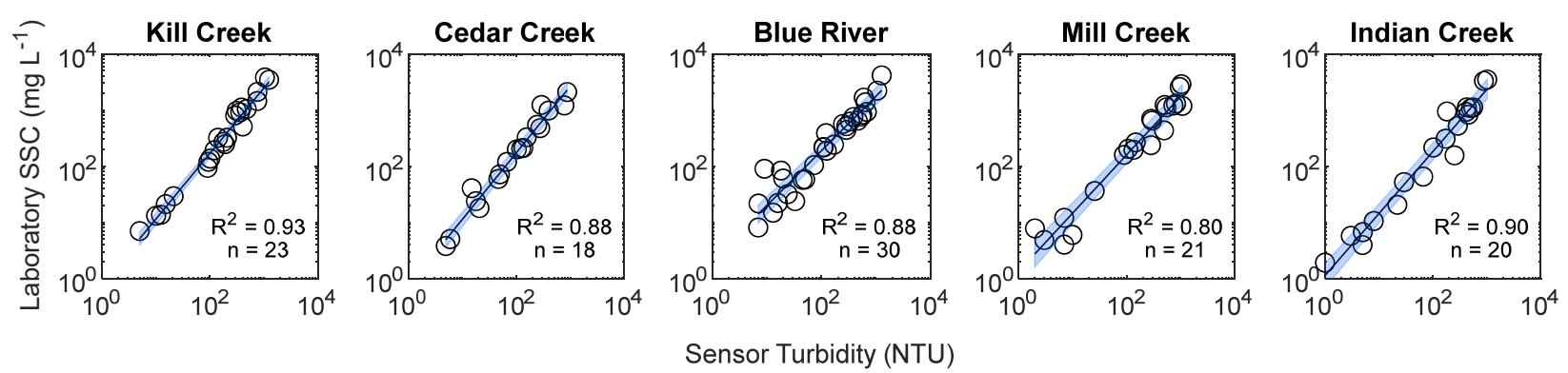

Figure S2 Turbidity sensor regressions against laboratory-measured suspended sediment concentration $(S S C)$, with $95 \%$ prediction interval, for the five studied watersheds 

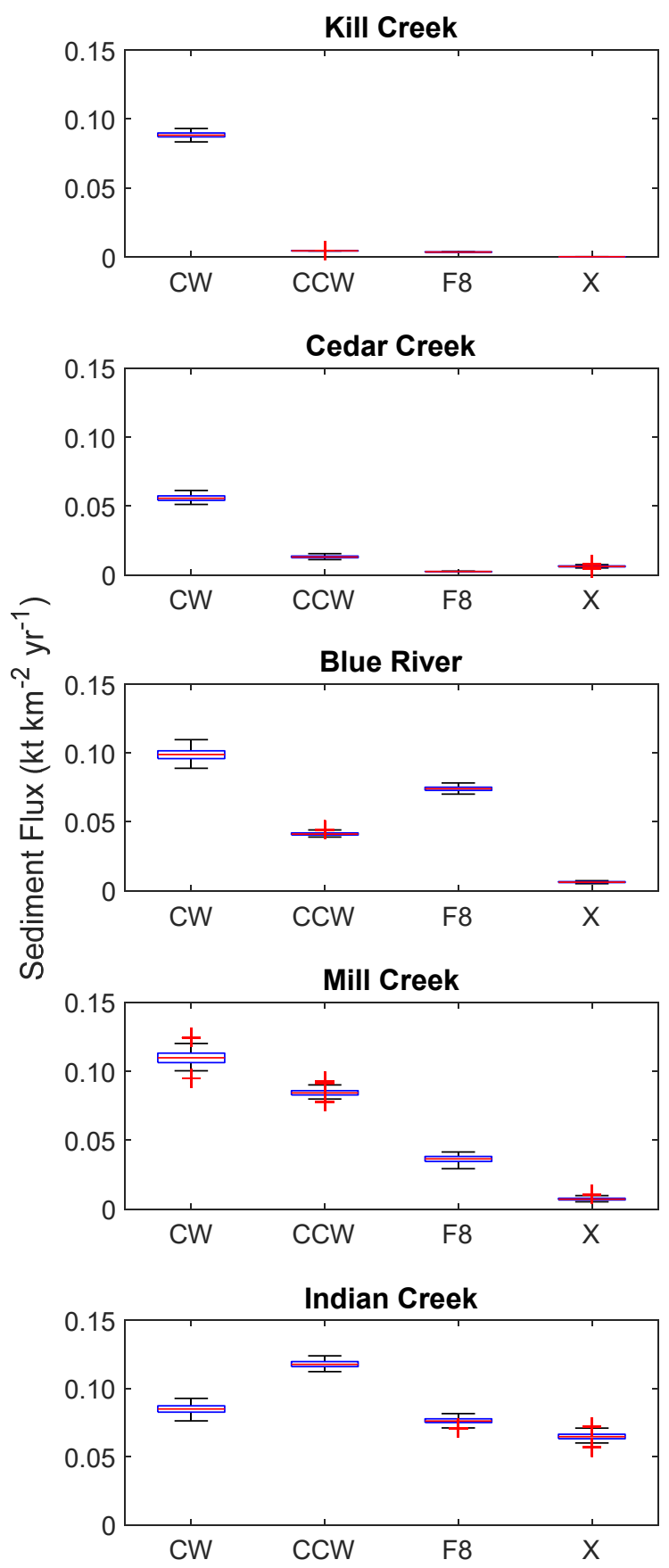

Figure S3 Sediment flux over the length of study period as a function of hysteresis type for the five studied watersheds. Prediction bounds on results incorporate the uncertainty in measuring discharge and turbidity. Legend: CW (clockwise), CCW (counter-clockwise), F8 (figure-eight), and X (complex). 


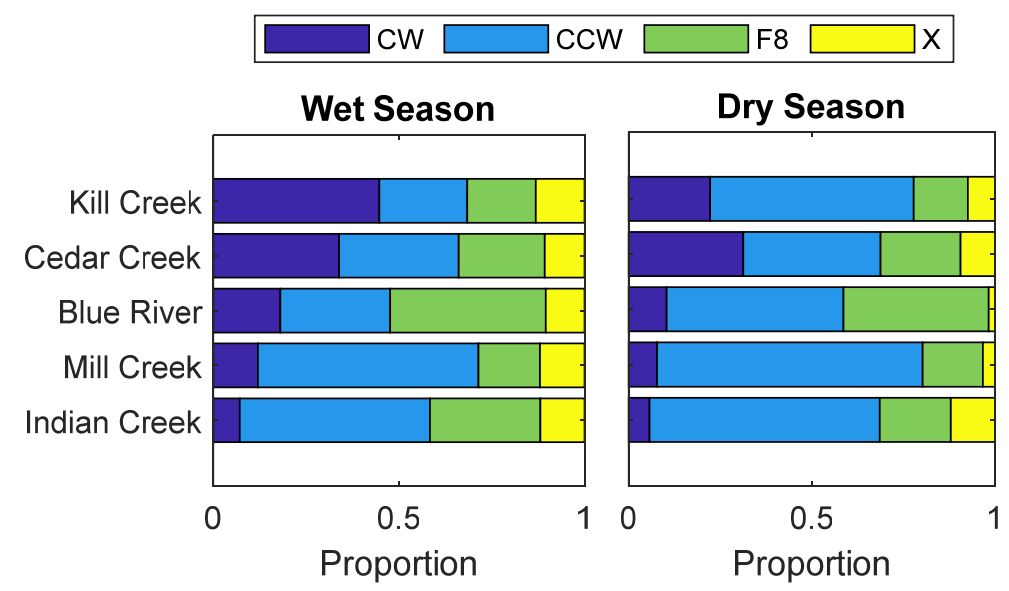

Figure S4 Seasonality of different hysteresis types for each study watershed. Legend: CW (clockwise), CCW (counter-clockwise), F8 (figure-eight), and X (complex). 


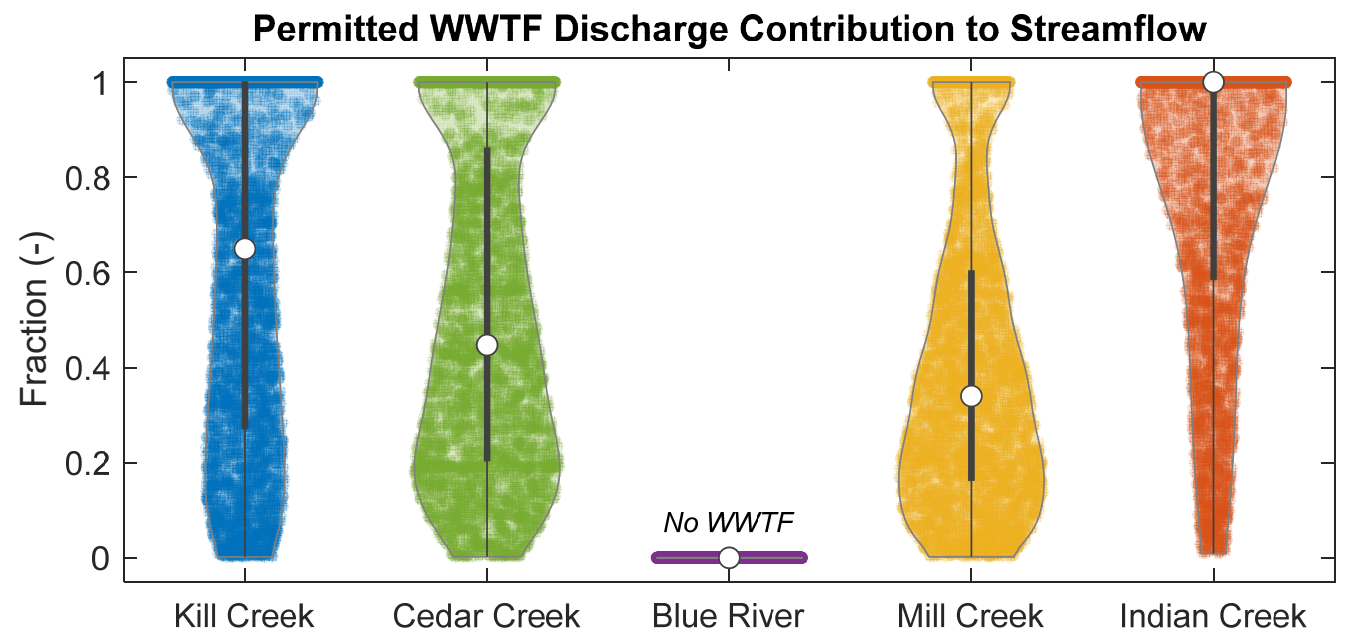

Figure S5 Violin plot of permitted wastewater treatment facility (WWTF) discharge as a fraction of daily streamflow for the studied watersheds. The white circle indicates the median of the probability density function and the dark bars extend to the inter quartile range. 